\title{
Desastres biológicos e sua relação com a saúde coletiva: uma análise dos artigos publicados no estado do Paraná, Brasil
}

\author{
Biological disasters and their relation to public health: an analysis \\ of articles published in the State of Paraná, Brazil
}

Fernanda Enko dos Santos Batista (https://orcid.org/0000-0002-4249-3531) ${ }^{1}$

Eduardo Gomes Pinheiro (https://orcid.org/0000-0001-5408-7883) ${ }^{1}$

Larissa Maria da Silva Ferentz (https://orcid.org/0000-0001-5804-0361) ${ }^{2}$

Danyelle Stringari (https://orcid.org/0000-0002-3532-7914) ${ }^{1}$
${ }^{1}$ Centro Universitário de Estudos e Pesquisas sobre Desastres. Av. Prefeito Lothário Meissner 350, Jardim Botânico. 82590300 Curitiba PR Brasil. fernandaenko1@gmail.com ${ }^{2}$ Pontifícia Universidade Católica do Paraná. Curitiba PR Brasil.

\begin{abstract}
This study emphasizes the relationship between biological disasters and public health through the systematization of the articles produced by institutions of the State of Parana in the last few decades. These were selected using key words defined in Codar and Cobrade in the Journal Portals of the Capes, Web of Science, Scopus, PubMed, Redulac, Spell, SciELO, Medline and Bireme databases. As a result, 318 articles were located from 1970 onwards, with a peak in 2012. Within the areas of knowledge published on the subject, 29\% of the articles are linked to health sciences, followed by $28 \%$ related to agrarian sciences. In the analysis of the language most used, although the English language was universal, Portuguese was predominant in most articles (84\%). With respect to disaster phases, more than $90 \%$ of the publications are on disaster risk management, with a small amount of works on the biological disaster per se. Finally, in the comparison of the key words of the articles over the ensuing years, the key word most mentioned is leishmaniasis, with the bulk of mentions between 2001 and 2010. This study showed that the areas are integrated, although there is a difficulty in correlation between issues such as disasters and the spread of diseases. Key words Biological disaster, Public health, Natural disasters, Risk management, Health promotion
\end{abstract}

Resumo Este estudo enfatiza a relação dos desastres biológicos com a saúde coletiva por meio da sistematização dos artigos produzidos por instituições do Paraná nas últimas décadas. Esses foram selecionados por palavras-chave definidas na Codar e Cobrade nas bases de dados do Portal de Periódicos Capes, Web of Science, Scopus, PubMed, Redulac, Spell, SciELO, Medline e Bireme. Como resultado, foram encontrados 318 artigos a partir de 1970, com auge em 2012. No âmbito das áreas de conhecimento que publicaram sobre o tema, $29 \%$ dos artigos estão vinculados às ciências da saúde, seguido de $28 \%$ das ciências agrárias. $\mathrm{Na}$ análise do idioma mais utilizado, apesar da língua inglesa ser universal, o português liderou na maioria dos artigos (84\%). E quanto às fases do desastre, mais de $90 \%$ das publicações são sobre a gestão de risco de desastre, tendo uma pequena quantidade de trabalhos sobre o desastre biológico propriamente dito. Por fim, na comparação das palavras-chave dos artigos com os anos decorrentes, a palavra-chave mais mencionada é a leishmaniose, com auge de citação entre os anos de 2001 e 2010. O presente estudo expôs que as áreas estão integradas, porém nota-se uma difculdade de correlação entre temas como desastres e propagação de doenças.

Palavras-chave Desastre biológico, Saúde coletiva, Desastres naturais, Gestão de riscos, Promoção da saúde 


\section{Introdução}

Conforme a Estratégia Internacional para a Redução de Desastres da Organização das Nações Unidas (EIRD/ONU), desastre é uma "séria interrupção do funcionamento de uma comunidade ou sociedade, que causa perdas humanas e/ou importantes impactos ou perdas materiais, econômicas ou ambientais que excedem a capacidade da comunidade ou sociedade afetada de lidar com a situação utilizando seus próprios recursos"'. E segundo o glossário da Defesa Civil, um desastre é o resultado de eventos extremos adversos, naturais ou antrópicos sobre um território ou um ecossistema, causando danos humanos, materiais ou ambientais e consequentes prejuízos econômicos e sociais ${ }^{2}$.

Eles ocorrem em todos os continentes, especialmente em regiões consideradas como áreas de risco. Em uma escala global, cerca de três quartos da população do planeta vivem em áreas afetadas por desastres (terremotos, ciclones tropicais, inundações, seca, dentre outros). Dessa fração, $85 \%$ das pessoas expostas a desastres de origem natural vivem em países de médio a baixo desenvolvimento ${ }^{3}$.

Nesse contexto, a saúde ambiental deveria ser prioridade por ser intersetorial e multidisciplinar, pois está diretamente relacionada à saúde humana. Esta tende ao controle social voltado para o bem-estar da população por meio de ações de sustentabilidade. Há uma demanda expressiva de profissionais da saúde solicitando a manutenção e a preservação ambiental, a fim de minimizar os impactos na saúde populacional ${ }^{4}$.

Assim, doenças como dengue, zika, chikungunya, febre amarela, leishmaniose, malária, peste e tripanossomíase são consideradas como desastres de grande preocupação para o Brasil. Os casos de epidemias, surtos epidêmicos e hiperendêmicos são considerados desastres humanos de causas biologicas, que podem surgir ou se intensificar complexificando os desastres naturais ${ }^{5}$.

Nessa situação, a biossegurança possui elementos objetivos para estabelecer ações preventivas e procedimentos capazes de controlar, suavizar e/ou eliminar os riscos, especialmente o biológico. Enfatiza-se que os desastres são diferenciados principalmente em função de sua origem, isto é, da natureza do fenômeno que o desencadeia, podendo ser naturais, antropogênicos e mistos ${ }^{6}$.

Os desastres naturais são de extrema importância e analisando seu impacto na saúde percebe-se a exposição da população nas condições de vulnerabilidade social e ambiental e na potencialidade de riscos e danos à população. Dessa forma, esses impactos refletem na população de diferentes formas e durações. Em curto prazo, seriam os feridos decorrentes do desastre, podendo ser ferimentos leves, graves ou mortalidade. As síndromes de média duração são as doenças que surgem após o prazo de algumas semanas, como leptospirose e diarreia infecciosa e as de longa são doenças psicossociais e comportamentais, desnutrição, entre outras? ${ }^{7}$.

A ocorrência de um desastre resulta da combinação de fatores importantes para a Saúde Pública: 1) a ocorrência de uma ameaça natural; 2) uma população exposta; 3) as condições de vulnerabilidade social e ambiental desta população; e 4) insuficientes capacidades ou medidas para reduzir os potenciais riscos e os danos à saúde da população ${ }^{8}$.

Uma situação de desastre envolve cenários de risco diferentes e interligados. É necessário abordar a gestão de riscos de maneira integrada para lidar com esta complexidade, contemplando atividades nas etapas de prevenção, mitigação, preparação, resposta e recuperação. Com isso, o processo de gestão do risco de desastre envolve ações de avaliação do risco (antes da ocorrência), da assistência ao desastre (durante a ocorrência) e de recuperação dos seus efeitos (concomitantemente com evento), e uma das principais características é planejar e agir de forma intersetorial $^{9}$. Nesse processo, o olhar sobre o território é essencial para conhecer o cenário existente, suas potenciais ameaças ou perigos, bem como as vulnerabilidades, além dos atores envolvidos, governamentais e não governamentais ${ }^{10}$.

Buscando a redução dos riscos de desastres e a resiliência, a Organização das Nações Unidas lançou por meio da Estratégia Internacional para Redução de Desastres das Nações Unidas a campanha "Construindo Cidades Resilientes". A campanha busca convencer líderes e gestores públicos locais a comprometerem-se com o cumprimento dos "Dez Passos Essenciais Para Construir Cidades Resilientes" e trabalhar o desenvolvimento de soluções inovadoras que engajem governos locais na redução de risco ${ }^{11}$.

Conforme a campanha, o risco de não se atentar à prevenção dos desastres pode levar a sérios problemas econômicos, assim como à perda da confiança da população e de investidores. Pequenos e médios impactos causados por desastres e eventos intensos isolados podem comprometer seriamente os serviços essenciais, como os sistemas de distribuição de alimentos, água, saú- 
de, transporte, lixo e comunicações localmente, e na sua relação com o resto do mundo.

Pensando nesse sentido, o quinto passo dos 10 existentes na campanha é sobre a proteção dos serviços essenciais: a educação e a saúde. Essas instalações devem ter uma atenção especial para garantir a sua continuidade nos momentos de maior necessidade. São locais responsáveis por funções essenciais durante e depois de um desastre e precisam ser planejados e construídos a partir de altos padrões de resiliência ${ }^{11}$.

A exposição a riscos e condições de vulnerabilidade a desastres são fatores a serem considerados no processo de manejo e gerenciamento dos riscos de desastres, sendo necessário seu enfoque por parte das políticas, dos profissionais e dos serviços de saúde. Assim, há necessidade de explorar a relação intrínseca entre a ocorrência de desastres, a saúde da população e as condições de vulnerabilidade ${ }^{12}$.

Nesse contexto, é fundamental o registro e a análise das consequências dos desastres, de maneira a subsidiar políticas públicas capazes de reduzir as perdas, especialmente de vidas humanas ${ }^{13}$.

No âmbito da saúde pública, para que um evento se constitua em um desastre são necessários alguns fatores que devem ser abrangidos. Primeiramente, é necessário um evento detonador, conceituado como ameaça, que relaciona a qualidade dos eventos físicos que podem ser gerados com a dinâmica da natureza, como os eventos geológicos, hidrometeorológicos, biológico ou da sociedade (degradação ambiental ou ameaças tecnológicas como rompimentos de barragens, acidentes químicos e nucleares). Este evento resulta na exposição de populações humanas, gerando o potencial de danos e agravos à saúde. E estes serão mais ou menos graves conforme as condições de vulnerabilidade, que resultam tanto na propensão de uma comunidade ou sociedade de sofrer de modo mais intenso e grave os efeitos dos desastres, como também nas limitações das capacidades de redução de ris$\cos$ e de resiliência frente a estes eventos ${ }^{14}$. Cada evento, seja natural ou tecnológico, exemplifica um tema: os desastres, ainda muito pouco pesquisados e compreendidos no âmbito da Saúde Coletiva no país.

O desenvolvimento de estudos e pesquisas é fundamental para subsidiar as ações, permitindo o conhecimento e o acompanhamento dos riscos ambientais à saúde decorrentes dos eventos desastrosos, bem como das metodologias e tecnologias a serem utilizadas ${ }^{13}$.
A busca por dados sobre desastres, seja em termos de suas causas ou de suas consequências, tornou-se fundamental no período recente. Os tomadores de decisão estão utilizando cada vez mais esses dados, tanto para medidas mitigadoras, quanto para o monitoramento das áreas afetadas $^{13}$.

Dessa forma, a execução da campanha da ONU em conjunto com o presente trabalho se faz importante no planejamento de novas instalações de saúde pelos gestores públicos, principalmente no momento da criação dos planos de ação, na investigação das capacidades exigidas em situações de emergência e reconstrução, na avaliação dos padrões de segurança do local e da infraestrutura ${ }^{11}$.

Assim, o objetivo deste trabalho é associar os desastres naturais à saúde da população e demonstrar a relação dos artigos publicados pelas instituições do Paraná com os desastres biológicos codificados pelo Ministério da Integração, de modo a oferecer subsídios para uma melhor compreensão destes eventos, bem como auxiliar na tomada de decisão pelos gestores públicos em relação aos investimentos nas áreas da saúde que são prioritárias.

\section{Metodologia}

Foi realizada uma busca sobre artigos publicados por pesquisadores do estado do Paraná, que no seu contexto expressavam ou demonstravam risco, ameaça ou o próprio evento desastroso referente à área biológica. A escolha pelo estado do Paraná, como objeto de estudo, deu-se pela existência da Rede Estadual de Pesquisa, Ensino, Extensão e Inovação Tecnológica - Redesastre, instituída pelo Decreto Estadual n ${ }^{0} 12.445 / 14^{15}$. A Redesastre é a primeira rede oficialmente criada no Brasil com a finalidade de tratar o tema, tendo como propósito a cooperação e o intercâmbio científico/tecnológico entre pesquisadores e instituições, direcionado à redução de riscos e desastres no estado. A Redesastre é coordenada pelo Centro Universitário de Estudos e Pesquisas sobre Desastres - CEPED/PR e conta hoje com mais de 25 instituições cooperadas, dentre elas, a Organização das Nações Unidas (ONU), a qual tem o seu reconhecimento e parceria para capacitação dos gestores públicos estaduais e municipais na Campanha Global da ONU "Construindo Cidades Resilientes".

O levantamento da produção científica foi realizado nas bases de dados: Portal de Periódicos 
Capes, Web of Science, Scopus, PubMed, Redulac, Spell, SciELO, Medline e Bireme. A busca foi realizada por meio de palavras-chave relacionadas aos desastres naturais biológicos citados na Codificação Brasileira de Desastres (Cobrade) ${ }^{16}$ e na Codificação de Desastres, Ameaças e Riscos (Codar) ${ }^{17}$ (Quadro 1), totalizando 53 elementos de busca diferentes.

As publicações que foram selecionadas por estas palavras-chave foram lidas integralmente para conferência: se a produção foi executada por instituição de ensino e pesquisa do Paraná e se o assunto do artigo seria de fato sobre desastres, ameaças e riscos.

O trabalho definiu a escolha por artigos em busca de publicações de ampla difusão. Delimi- tamos o idioma como português, inglês e espanhol em busca de maior repertório de desastres e versões situadas não somente na língua nacional. Para dar conta do critério de regionalidade, foram considerados todos os artigos que tivessem ao menos um autor de instituição paranaense na equipe. A produção não foi delimitada por período, em virtude da possibilidade de abordar as publicações sobre o assunto desde o início da operação das bases de dados.

Os artigos selecionados foram organizados em planilhas com auxílio do programa Excel. Foram excluídos artigos duplicados, publicados em conferências, livros, capítulo de livros, patentes e séries. Cabe ressaltar também que foram apenas utilizados os artigos disponibilizados integral-

Quadro 1. Termos utilizados na pesquisa sobre desastres presentes no Cobrade e Codar.

\begin{tabular}{|c|c|c|c|c|}
\hline \multicolumn{5}{|c|}{ Cobrade } \\
\hline \multirow{8}{*}{ 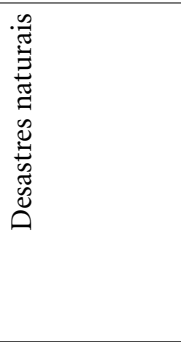 } & \multirow{8}{*}{ 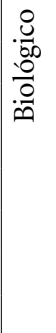 } & \multirow[t]{4}{*}{ Epidemias } & \multicolumn{2}{|c|}{ Doenças infecciosas virais } \\
\hline & & & \multicolumn{2}{|c|}{ Doenças infecciosas bacterianas } \\
\hline & & & \multicolumn{2}{|c|}{ Doenças infecciosas parasíticas } \\
\hline & & & \multicolumn{2}{|c|}{ Doenças infecciosas fúngicas } \\
\hline & & \multirow{4}{*}{$\begin{array}{l}\text { Infestações/ } \\
\text { Pragas }\end{array}$} & \multicolumn{2}{|c|}{ Infestações de animais } \\
\hline & & & \multirow[t]{2}{*}{ Infestações de algas } & Marés Vermelhas \\
\hline & & & & Cianobactérias em reservatórios \\
\hline & & & \multicolumn{2}{|l|}{ Outras infestações } \\
\hline \multicolumn{5}{|c|}{ Codar } \\
\hline \multirow{12}{*}{$\begin{array}{l}\text { Relacionados } \\
\text { à água e/ou } \\
\text { Alimentos }\end{array}$} & \multicolumn{2}{|c|}{ Doença do sono } & \multirow{6}{*}{$\begin{array}{l}\text { Relacionados a } \\
\text { Vetores Biológicos }\end{array}$} & Dengue \\
\hline & \multicolumn{2}{|c|}{ Amebíase } & & Febre Amarela \\
\hline & \multicolumn{2}{|c|}{ Cólera } & & Leishmaniose \\
\hline & \multicolumn{2}{|c|}{ Diarreias } & & Malária \\
\hline & \multicolumn{2}{|c|}{ Salmoneloses } & & Peste \\
\hline & \multicolumn{2}{|c|}{ Febre Tifoide } & & Tripanossomíase \\
\hline & \multicolumn{2}{|c|}{ Febre Paratifoide } & \multirow{6}{*}{$\begin{array}{l}\text { Relacionados } \\
\text { por Sangue e } \\
\text { outras Secreções } \\
\text { Contaminadas }\end{array}$} & Hepatite a vírus B \\
\hline & \multicolumn{2}{|c|}{ Shigeloses } & & Hepatite a vírus $\mathrm{C}$ \\
\hline & \multicolumn{2}{|c|}{ Intoxicações Alimentares } & & Síndrome da Imunodeficiência \\
\hline & \multicolumn{2}{|c|}{ Hepatite a Vírus A } & & Adquirida \\
\hline & \multicolumn{2}{|c|}{ Polimielite } & & Outras Doenças Sexualmente \\
\hline & \multicolumn{2}{|c|}{$\begin{array}{l}\text { Outras doenças transmitidas por } \\
\text { água e alimentos }\end{array}$} & & Transmissíveis \\
\hline \multirow{9}{*}{$\begin{array}{l}\text { Relacionados } \\
\text { com Doenças } \\
\text { transmitidas } \\
\text { por Inalação }\end{array}$} & \multicolumn{2}{|c|}{ Coqueluche } & \multirow{9}{*}{$\begin{array}{l}\text { Relacionados por } \\
\text { outros mecanismos } \\
\text { de transmissão }\end{array}$} & Leptospirose \\
\hline & Dift & & & Raiva \\
\hline & Grip & & & Tétano \\
\hline & Influ & & & Schistossomose \\
\hline & Men & & & Esquistossomose \\
\hline & Sara & & & Outras doenças transmitidas \\
\hline & Tub & & & por outros ou por mais de \\
\hline & Out & iratórias & & ummecanismo de transmissão. \\
\hline & Agu & & & \\
\hline
\end{tabular}


mente de forma gratuita, podendo estar em português, inglês ou espanhol. Com o encerramento das pesquisas, foram realizadas as análises estatísticas descritivas e a produção dos gráficos.

\section{Resultados e discussão}

Como resultado da busca nas bases de dados, foram encontrados 318 artigos relacionados aos desastres naturais biológicos.

Analisando a série histórica do volume de artigos publicados sobre o tema, vemos que a primeira publicação foi em 1970 e a sua explanação foi sobre a remediação da Leishmaniose, tendo por título "Tratamento da Leishmaniose tegumentar americana pelo Niridazol". No aspecto quantitativo, o aumento das publicações teve início em 1999, sendo que em 2008 houve o primeiro movimento de artigos sobre a área da saúde e dos desastres, com 22 publicações. Destaca-se também que em 2012 houve o auge das publicações, com 26 artigos na área. No ano de 2008 a maioria das publicações era na área das ciências da saúde (42\%), seguido das ciências agrárias (25\%) e, em 2012, vemos a inversão, com $44 \%$ das publicações na área das ciências agrárias e $22 \%$ nas ciências da saúde. E nota-se uma tendência crescente para os próximos anos quanto à produção sobre o assunto (Gráfico 1).
Dos artigos seletos pelo tema, foi realizado um arranjo pelas áreas de conhecimento de acordo com a classificação da Capes (http:// www.capes.gov.br/), utilizando-se, para isso, os cursos em que o pesquisador estava vinculado. A maioria das publicações (42\%) está associada à área da saúde, seguido pela área das ciências agrárias (27\%) e pelas ciências biológicas (16\%). $\mathrm{Na}$ análise dos artigos de menor frequência, ressalta-se um que é vinculado às ciências exatas. Este foi selecionado pela palavra-chave "dengue" e abordou a detecção e prevenção da dengue e sua densidade populacional, com o título "Developing new approaches for detecting and preventing Aedes Aegypti population outbreaks: basis for surveillance, alert and control system". Outros artigos classificados conforme as buscas das palavras-chave estão em outras áreas do conhecimento.

De todos os artigos selecionados, $84 \%$ estão na língua portuguesa e o restante em inglês (16\%), dessa forma, nenhum artigo em espanhol correspondia à pesquisa.

Se por um lado o idioma inglês é universal e está ao alcance da maioria dos pesquisadores, para muitos gestores, profissionais de saúde e defesa civil, além da população em geral, poucos artigos sobre o tema foram encontrados. Neste sentido, a disponibilização de conteúdo científico e técnico nos idiomas inglês e espanhol de

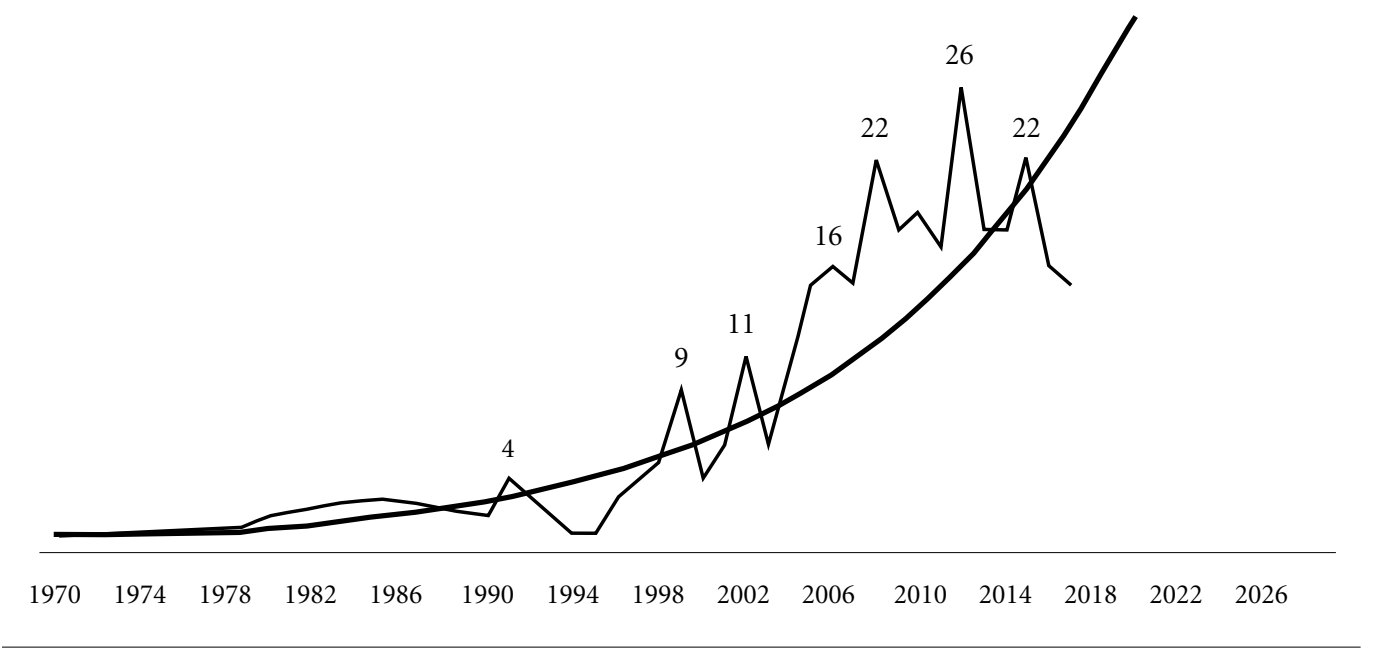

Gráfico 1. Aspecto temporal das publicações na área da saúde a partir de palavras-chave referidas na CODAR e COBRADE. 
forma gratuita, facilitaria o intercâmbio entre a academia, as empresas, os serviços públicos e a sociedade e aumentaria a possibilidade de expansão do assunto.

Também foi realizada a classificação dos artigos conforme o seu título e o seu conteúdo, com o objetivo de avaliar a incidência da pesquisa na gestão de risco ou apenas no gerenciamento do desastre. Destes, $94 \%$ correspondem à gestão de risco e $6 \%$ estavam relacionados com a gestão do desastre, propriamente dito. $\mathrm{O}$ que indica que o Paraná está criando uma cultura de prevenção, com o intuito de reduzir as ameaças e suas consequências. Anteriormente, a única responsável pela gestão de risco em âmbito nacional era a Secretaria Nacional de Defesa Civil, mas segundo o estudo novos atores estão surgindo.

Reunidas todas as palavras-chave houve uma comparação destas com os anos de publicação para cada um dos artigos.

Com os dados temporais classificados em décadas, percebe-se que a palavra-chave mais utilizada é "leishmaniose", tendo maior número de citações entre os anos de 2001 a 2010. O estudo da leishmaniose de forma contínua por quase todos os anos de pesquisa justifica-se pelo fato do Paraná ser o estado do Sul do Brasil que mais tem casos confirmados na região desde o ano de 1990 até 2016, conforme os dados do Sistema de Informação de Agravos de Notificação ${ }^{17}$.

A segunda palavra-chave mais citada é a "epidemiologia", só não mencionada nas publicações dos anos de 1970 a 1980. "Parasitologia" e "Toxoplasmose" são a terceira e quarta palavraschave mais mencionadas, respectivamente, de tal modo que a primeira só não obteve citação entre os anos de 1981 a 1990, enquanto que a segunda teve as maiores citações entre os anos de 2011 a julho de 2018. Em seguida, ainda resultaram em grandes citações os termos de "Erosão" e "Saúde", e em poucas citações os termos de "Prevenção", "Tuberculose", "Tripanossomíase Americana", "Ecologia de Vetores" e "Infecção Neonatal".

$\mathrm{Na}$ análise dos artigos selecionados pelas palavras da Codificação Brasileira de Desastres (Cobrade), 50\% apresentaram o termo doenças infecciosas parasíticas, enquanto $19 \%$ e $8 \%$ demonstraram vínculo com as doenças infecciosas virais e doenças infecciosas bacterianas, respectivamente. Sendo que o restante da porcentagem ficou distribuído nos outros termos da codificação (Gráfico 2).

$\mathrm{Na}$ análise dos termos da Codificação de Desastres, Ameaças e Riscos (Codar), de acordo com os anos de publicação, dentre todas as palavras- chave presentes na codificação, a que mais obteve publicações sobre o tema são as outras doenças transmitidas pela água ou alimentos. E observase que esse termo vem sendo utilizado com mais frequência na última década. Ressaltando que na codificação há apenas 11 doenças citadas dentre todas as doenças transmitidas por esse meio, ou seja, a grande maioria das doenças foi englobada nessa palavra-chave. A leishmaniose foi o segundo termo que mais apresentou artigos e este se manteve estável desde o início das publicações (Gráfico 3).

Inúmeras doenças não são citadas nas codificações, mesmo que a maioria delas sejam doenças incidentes. Dessa forma, se observa uma grande quantidade de estudos sobre enfermidades pouco divulgadas pelo poder público. Selecionando, por exemplo, o termo "doenças transmitidas por vetores", existem vários artigos de doenças que foram selecionados pelo fato de corresponder a esse termo mesmo não estando presentes nas codificações como: a toxoplasmose, a cisticercose, a criptosporidiose, a toxocaríase, a ancilostomose, a ascaridíase, a fasciolose, a giardíase, a amebíase, a doença de chagas, a estrongiloidíase, entre diversas outras enfermidades negligenciadas.

Segundo a Organização Mundial da Saúde, doenças negligenciadas são aquelas que não só prevalecem em condições de pobreza, mas também contribuem para a manutenção do quadro de desigualdade, pois representam forte entrave ao desenvolvimento dos países. Os investimentos em pesquisa e desenvolvimento não priorizam essa área, não despertam interesse das grandes empresas farmacêuticas multinacionais, que não veem nessas doenças a oportunidade de obter compradores de seus produtos. O conhecimento produzido não se reverte em avanços terapêuticos, com novos fármacos e métodos diagnósti$\cos ^{19}$.

O Brasil colabora com a maior parte da carga de doenças tropicais negligenciadas na América Latina e Caribe. Isto significa que grande parte dos 40 milhões da população mais pobre do Brasil está infectada por uma ou mais doenças tropicais negligenciadas ${ }^{20}$.

É necessário incentivar o estabelecimento de mecanismos apropriados para intensificar os investimentos em infraestrutura e qualificação de pessoal, dentro de uma visão estratégica que contemple a continuidade.

No âmbito da Saúde Coletiva, a situação de saúde corresponde a formas de concretização dos processos mais gerais que caracterizam a estrutura e a dinâmica de uma sociedade. Isto envolve, 


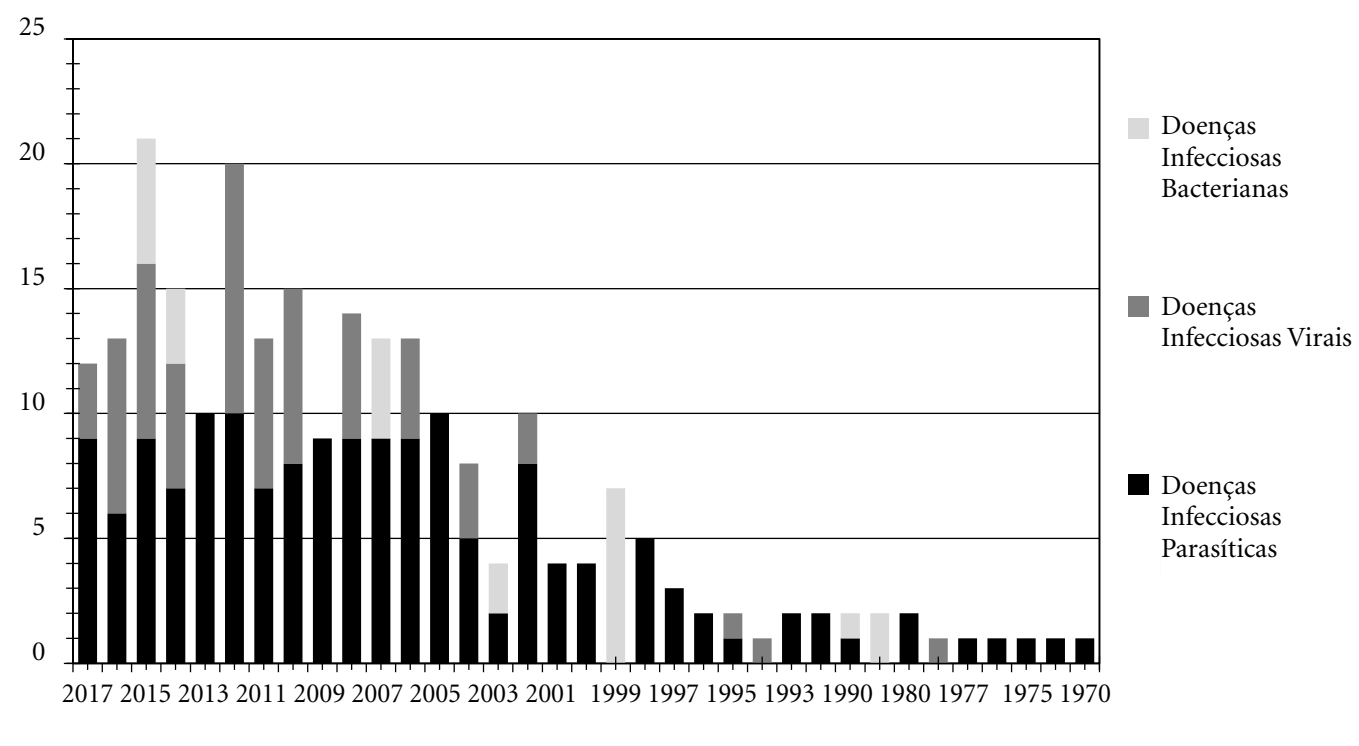

Gráfico 2. Análise quantitativa dos artigos conforme termos dos desastres naturais biológicos da Classificação e Codificação Brasileira de Desastres (COBRADE) de acordo com o aspecto temporal.

Fonte: os autores.

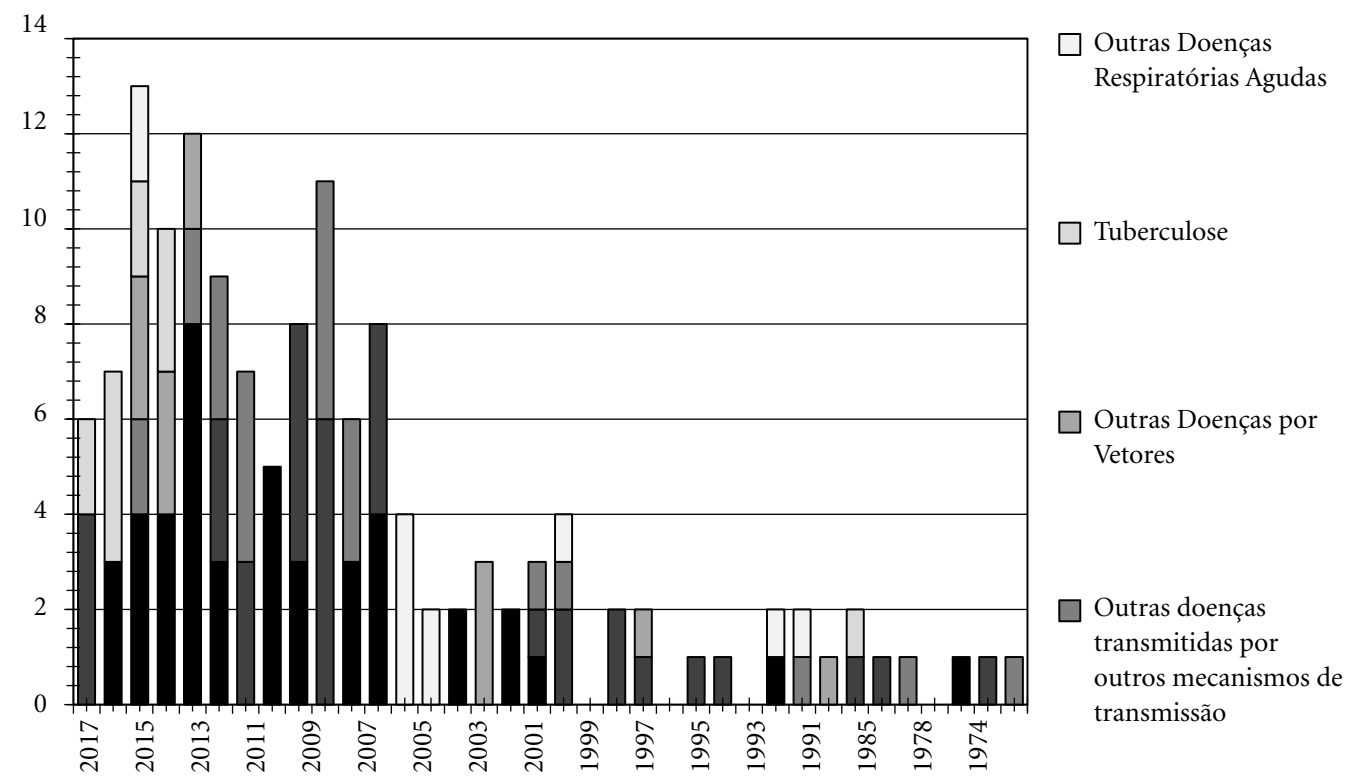

Gráfico 3. Análise quantitativa dos artigos conforme termos dos desastres naturais biológicos da Codificação de Desastres, Ameaças e Riscos (CODAR) de acordo com o aspecto temporal. 
por um lado, os processos sociais e econômicos e, por outro, também os relacionados às mudanças da situação ambiental, resultantes das alterações nos ciclos do clima e das águas, até amplos processos de degradação dos recursos naturais disponíveis, podendo se caracterizar como desastres.

Conceitualmente, os desastres devem ser compreendidos a partir das abordagens complexas, contemplando um amplo diálogo com múltiplos campos do conhecimento para operacionalizar procedimentos voltados a mitigar riscos, contribuindo assim para ações preventivas voltadas para a saúde pública.

A natureza interdisciplinar e intersetorial dos desastres necessariamente obriga a Saúde Coletiva a ter uma ampla visão sobre os mesmos, bem como a formular políticas e ações que atuem diretamente sobre seus determinantes socioambientais. Os desastres não acontecem sem a ocorrência de ameaças naturais, bem como que os impactos sobre a saúde não se realizam sem estas e sem as exposições, que podem ser agravadas em condições de vulnerabilidade socioambiental.

\section{Colaboradores}

FES Batista foi responsável de pesquisa dos artigos, LMS Ferentz da elaboração do corpo do texto, D Stringari e EG Pinheiro pela revisão do artigo.

\section{Conclusão}

O presente estudo expôs que as áreas de saúde e eventos extremos estão integradas, porém, que foi notada uma dificuldade de correlação entre temas de desastres e a propagação de doenças, por exemplo, nas pesquisas realizadas pelas instituições de ensino e pesquisa do estado do Paraná.

Outro ponto a ser destacado, é que dos 318 artigos analisados, foi observado um aumento crescente de publicações a partir dos anos 2000, com ênfase no ano de 2012. Em decorrência aos eventos caracterizados como "Águas de Março", em 2011, diversos artigos sobre desastres e seus impactos na sociedade foram publicados, sendo um forte indicador de que quando estes grandes eventos ocorrem, as pessoas tendem a buscar e compartilhar informações para entender os fenômenos e, por conseguinte, apresentar soluções para os mesmos.

Espera-se com este tipo de análise contribuir para que o setor de saúde avance no debate sobre este tema, não só estruturando uma melhor resposta para as ações de vigilância e atenção no curto prazo, mas também de reabilitação e recuperação das condições de saúde, da reconstrução da vida das populações expostas, além da formulação de políticas intersetoriais de prevenção dos mesmos. 


\section{Referências}

1. United Nations. International Strategy for Disaster Risk Reduction (UNISDR). UNISDR terminology on disaster risk reduction. Geneva: UNISDR; 2009. [acessado 2018 Jul 17]. Disponível em: http://www.unisdr. org/eng/terminology/ terminology-2009-eng.html

2. Castro ALC, coordenador. Glossário de defesa civil, estudos de risco e medicina dos desastres [Internet]. $5^{\mathrm{a}} \mathrm{ed}$ Brasília: Ministério do Planejamento e Orçamento; 2009. [acessado 2018 Jul 17]. Disponível em: http:// www.defesacivil.mg.gov.br/images/documentos/ Defesa $\% 20 \mathrm{Civil} /$ manuais/GLOSSARIO-DicionarioDefesa-Civil.pdf

3. Hualou L. Disaster prevention and management: a geographical perspective. Disaster Advances 2011; 4(1):3-5.

4. Brasil. Ministério da Saúde (MS). Subsídios para construção da Política Nacional de Saúde Ambiental. Brasília: Editora do Ministério da Saúde; 2007.

5. Brasil. Ministério da Integração Nacional. Manual de desastres: desastres humanos de natureza biológica. Brasília; SEDEC; 2005

6. Cardoso T, Costa F, Navarro M. Biossegurança e desastres: conceitos, prevenção, saúde pública e manejo de cadáveres. Physis 2012; 22(4):1523-1542.

7. Berté R, Rodrigues ICG, Busato IMS, Garcia IF, Ribas JLC, Santos VLP. Avaliação do pensamento integrador: a inter-relação entre desastres naturais e a saúde. Revista Saúde e Desenvolvimento 2017; 11(9):308-317.

8. Brasil. Ministério da Saúde (MS). Desastres naturais e saúde: análise do cenário de eventos hidrológicos no Brasil e seus potenciais impactos sobre o Sistema Único de Saúde. Boletim Epidemiológico 2018; 49(10).

9. Pinheiro EG. Orientações para o Planejamento em Proteção e Defesa Civil: Plano Setorial de Proteção e Defesa Civil. Curitiba: FUNESPAR; 2017. [acessado 2018 Jul 17]. Disponível em: http://www.ceped.pr.gov.br/arquivos/File/ GuiaPlanejamentoPlanoSetorialPDC.pdf

10. Kleim M. Preventing disasters: public health vulnerability reduction as a sustainable adaptation to climate change. Prehospital and Disaster Medicine 2011; 28(1):45-45.

11. United Nations. International Strategy for Disaster Risk Reduction (UNISDR). Como Construir Cidades Mais Resilientes: Um Guia Para Gestores Públicos Locais (2005 - 2015). Genebra: UNISDR; 2012. [acessado 2018 Jul 17]. Disponível em: https://www.unisdr. org/files/26462_ guiagestorespublicosweb.pdf

12. Brasil. Ministério da Saúde (MS). VIGIDESASTRES Programa Nacional de Vigilância em Saúde Ambiental dos Riscos Decorrentes dos Desastres Naturais. Brasília: MS; 2007.

13. Carmo RL, Anazawa TM. Mortalidade por desastres no Brasil: o que mostram os dados. Cien Saude Colet 2014; 19(9):3669-3681.
14. Freitas CM, Carvalho ML, Ximenes EF, Arraes EF, Gomes JO. Vulnerabilidade socioambiental, redução de riscos de desastres e construção da resiliência - lições do terremoto no Haiti e das chuvas fortes na Região Serrana, Brasil. Cien Saude Colet 2012; 17(6):15771586.

15. Paraná. Decreto Estadual $n^{\circ} 12.445 / 14$, de 23 de outubro de 2014. Instituição da Redesastre. Diário Oficial do Paraná 2014; 23 out.

16. Brasil. Ministério da Integração. Classificação e Codificação Brasileira De Desastres - Cobrade. 2012. [acessado 2018 Jul 15]. Disponível em: http://www.mi.gov. $\mathrm{br} /$ defesa-civil/legislacoes

17. Secretaria Nacional de Defesa Civil (SEDEC). Codificação de Desastre, Ameaças e Riscos - Codar. Curitiba: SEDEC; 2011. [acessado 2018 Jul 15]. Disponível em: http://www.defesacivil.gov.br/codar/index.asp

18. Brasil. Ministério da Saúde (MS). Sistema de Informação de Agravos de Notificação - SINAN: Casos de Leishmaniose Tegumentar. 1990 a 2016. Brasília: MS; 2017. [acessado 2018 Jul 17]. Disponível em: http:// portalarquivos2.saude.gov.br/images/pdf/2017/setembro/14/LT-Casos.pdf

19. Brasil. Ministério da Saúde (MS). Doenças negligenciadas: estratégias do Ministério da Saúde. Rev Saude Publica 2010; 44(1):200-202.

20. Hotez P. The giant anteater in the room: Brazil's neglected tropical diseases problem. PLoS Neglected Tropical Diseases 2008; 2(1):77.

Artigo apresentado em 12/11/2018

Aprovado em 10/07/2019

Versão final apresentada em 12/07/2019

Editores-chefes: Romeu Gomes, Antônio Augusto Moura da Silva 
